\title{
INTERNAÇÃO COMPULSÓRIA DE DEPENDENTES QUÍMICOS: VIOLAÇÃO DO DIREITO DE LIBERDADE OU PROTEÇÃO DO DIREITO À VIDA?
}

\section{COMPULSORY INSULATION OF CHEMICAL DEPENDENTS: VIOLATION OF THE RIGHT OF FREEDOM OR PROTECTION OF THE RIGHT TO LIFE?}

\author{
Luis Fernando Gonçalves Pereira \\ Especialista em Direito Penal e Processo Penal pela Universidade de Uberaba (UNIUBE) \\ dirfernandoluis@gmail.com \\ Igor Machado Ricardo \\ Mestrando em Saúde do Trabalhador pela Universidade Federal de Uberlândia (UFU) \\ igormachadoricardo@hotmail.com \\ Rafael Lemes de Aquino \\ Mestre em Saúde do Trabalhador pela Universidade Federal de Uberlândia (UFU) \\ Doutorando em Ciências da Saúde pela UFU \\ rafael.aquino@ufu.br \\ Douglas Ataniel Alves Xavier \\ Mestre em Ciências da Saúde pela Universidade Federal de Uberlândia (UFU) \\ Enfermeiro Intensivista do HC-UFU \\ douglas.xavier@ufu.br
}

\begin{abstract}
RESUMO
Este trabalho versa sobre a internação compulsória de dependentes químicos e suas peculiaridades no âmbito do Direito Constitucional. Aborda as garantias constitucionais inerentes ao tema, especialmente o direito à vida, o direito à liberdade e o princípio da dignidade da pessoa humana. Estuda as comparações e o conflito existente entre os preceitos garantidos pela nossa Constituição Federal, tais como o direito à saúde, dignidade da pessoa humana e direito à liberdade. Analisa os tipos de internações psiquiátricas e o seu amparo legal. Apresenta um estudo sobre a ligação entre as drogas e a violência nos dias atuais, com base na doutrina e na jurisprudência que abordam o tema.
\end{abstract}

Palavras-chave: Princípios constitucionais. Dignidade da pessoa humana. Internação psiquiátrica. Direito à saúde. Direito à liberdade.

\begin{abstract}
This work deals with the compulsory hospitalization of drug addicts and their peculiarities in the Constitutional Law. Addresses the constitutional guarantees inherent in the subject, particularly the right to life, the right to liberty and the principle of human dignity. Studies the comparisons and the conflict between the provisions guaranteed by our Constitution, such as the right to health, human dignity and the right to freedom. Analyzes the types of psychiatric hospitalizations and their legal protection. Presents a study on the connection between drugs and violence today, based on the doctrine and jurisprudence that address
\end{abstract}

Keywords: Maria da Penha Law. Domestic Violence. Public Policy. Interdisciplinarity.

\section{INTRODUÇÃO}

O trabalho apresentado tem por escopo abordar a matéria da medida de internação compulsória utilizada aos dependentes químicos. Essa internação foi usada, muitas vezes, como um disfarce para

Recebido em: 19/03/2019

Aceito para publicação em: 30/03/2020. 
isolar determinados indivíduos do convívio social, que eram considerados como obstáculos para algumas pretensões econômicas, políticas e até mesmo social.

A questão principal da medida está na sua eficácia como tratamento e a polêmica em relação às questões sobre a liberdade do indivíduo como garantias do nosso Estado. Um dos objetivos do presente artigo é mostrar os prós e contras dessa modalidade de tratamento e o conflito de garantias gerado, apontando qual deles deve prevalecer.

Não se pode negar que o consumo de drogas tem aumentado significativamente nos dias atuais, primeiramente pelo fato do fácil acesso às drogas e o seu alto poder de dependência e destruição e, além disso, temos um alto índice de violência ligada ao tráfico de drogas. Assim, fica evidente que a população está à mercê dos traficantes e usuários, o que mostra a necessidade de políticas públicas para desenfrear o crescimento da violência e inserir na comunidade os dependentes perdidos no vício.

A medida de internação psiquiátrica pode ser uma grande arma no combate às drogas, entretanto, tem enfrentado alguns dilemas, como proteger o direito à vida ou a supressão da garantia de liberdade do paciente, uma vez que não é absoluta a certeza de recuperação dos pacientes submetidos ao tratamento. É nessa fase que nasce a discussão sobre a possível violação aos direitos fundamentais garantidos na nossa Constituição Federal.

Entretanto, algumas clínicas ao longo da história foram palcos de maus tratos e, muitas vezes, submetiam os internos a condições desumanas, o que prejudicou o propósito da medida, qual seja de recuperar os pacientes, promovendo a sua desintoxicação e reinserindo-os no meio social. $O$ dependente químico, quando se encontra no estado em que toma suas decisões colocando em primeiro lugar o vício, necessita urgentemente de ajuda para preservar a sua vida e, paralelamente, diminuir os males da droga dentro de nossa sociedade.

Dessa maneira fica evidente a necessidade do Estado e da própria família em intervir na intimidade do indivíduo e o internando em uma clínica de recuperação, ponderando o seu direito de liberdade em razão de resguardar a sua própria vida.

\section{ESTADO DEMOCRÁTICO DE DIREITO}

A expressão Estado Democrática de Direito deve ser compreendida não apenas no âmbito do direito administrativo, mas sim como aquela ordem jurídica em que se vive sobre o primado do direito, também conhecido como a era dos direitos, ou seja, um sistema de normas que tem o objetivo de garantir os direitos humanos e as liberdades fundamentais, e que disponha da lei como a expressão da vontade do seu povo.

E, não menos importante, trazer uma ideologia de igualdade na esfera privada e pública, de modo que tanto um cidadão comum quanto o poder do Estado fica submisso à Lei. Em outras palavras, não admitir que a aplicação das leis tenha resultados contrários aos preceitos constitucionais. Aliás, Bobbio (2010 p. 9-13) se utilizou de uma expressão diversa, conceituando os direitos fundamentais:

[...] os direitos do homem, por mais fundamentais que sejam, são direitos históricos, ou seja, nascidos em certas circunstâncias, caracterizadas por lutas em defesa de novas liberdades contra velhos poderes, e nascidos de modo gradual, não todos de uma vez e nem de uma vez por todas.

[...]o que parece fundamental numa época histórica e numa determinada civilização não é fundamental em outras épocas e em outras culturas.

Dessa maneira, um Estado sob este paradigma deve respeitar os direitos fundamentais das pessoas, ora resultado de lutas e conquistas presentes na história da humanidade. Nos limites deste trabalho, considerando que este Estado deve atender às necessidades das pessoas que se encontram sufocadas pelo vício dos tóxicos, apresentamos estes fundamentos teóricos que amparam a temática. 


\section{OS PRINCÍPIOS DO ESTADO DEMOCRÁTICO DE DIREITO INERENTES A SAÚDE}

Quando falamos em saúde devemos ligar diretamente com a vida e a existência digna do cidadão, de modo que para compreensão do presente trabalho acadêmico serão abordados no seu desenvolvimento três temas principais, quais sejam: o Direito à Vida, a Dignidade da Pessoa Humana e o Direito à Liberdade.

O direito à saúde está integrado aos direitos fundamentais garantidos pela nossa Carta Magna, estando inserido no título designado à ordem social, no seu artigo $6^{\circ}$, que traz como direitos fundamentais a educação, a saúde, o trabalho, o lazer, a segurança, entre outros.

Dentre o grupo dos direitos sociais, o direito a saúde de certa forma necessita de um cuidado especial em relação às outras garantias, foi colocado na Constituição em um capítulo próprio. Recebem, deste modo, uma proteção jurídica diferenciada no ordenamento jurídico. E o Estado brasileiro, pretendendo se tornar um Estado Democrático de Direito, tem a responsabilidade de promover o acesso desses direitos a todas as pessoas.

O Estado deve desenvolver políticas públicas para que todo ser humano possa gozar de uma melhor qualidade de vida e tem o dever de zelar e garantir esse direito de forma universal e gratuita. Sua garantia se manifesta em todas as etapas, seja de forma preventiva, de manutenção e de recuperação, com o intuito de superar as desigualdades sociais e alcançar a justiça social, haja vista que a saúde é direito de todos e dever do Estado, como previsto no artigo 196 da Constituição Federal.

Entretanto, uma questão de suma importância para o presente artigo é que devemos levar em conta que os recursos públicos destinados ao setor de saúde pública não são compatíveis com a demanda apresentada pelo nosso país, uma vez levado em conta todo o contingente populacional e territorial brasileiro. O que, consequentemente, dificulta a efetivação de tal direito extremamente difuso e, muitas vezes, leva a ocorrência de omissões na prestação desse comando constitucional.

\section{DIREITO À VIDA}

O direito à vida é o primeiro dos cinco valores fundamentais inspirados pela Constituição no caput do seu art. $5^{\circ}$, seguido da liberdade, igualdade, segurança e propriedade. Esse direito é o mais fundamental de todos, pois, como é entendido por Mendes; Coelho; Branco (2010, p. 441), a existência humana é o pressuposto elementar para o exercício de qualquer outro direito, sendo a premissa das garantias tuteladas pelo constituinte e não faria sentido algum declarar qualquer outro sem antes assegurar o próprio de estar vivo para usufruí-lo.

Reafirmando a relação entre o direito à vida e o ser humano, temos os ensinamentos de Mendes; Coelho; Branco (2010, p. 441):

A vida preservada e encarecida pelo constituinte há de ser toda a vida humana. Não é ocioso ressaltar que somente há vida humana em seres humanos, onde não há vida não há mais ser humano - assertiva que se completa com a noção igualmente necessária de que onde há ser humano, há vida. O direito à vida cola-se ao ser humano, desde que este surge e até o momento da sua morte.

O direito à vida está no rol dos direitos individuais ao passo que, essas garantias foram as primeiras a serem conquistadas pela população e se misturam na luta pela liberdade e segurança frente ao Estado e desta forma, este não pode desrespeitá-las.

Como consequência, o Brasil tem o dever de agir de forma a resguardar a inviolabilidade desse direito, bem como criar medidas públicas que tenham como objetivo zelar pela integridade física e mental das pessoas, o que, dessa maneira, faria com que o Estado proporcionasse à sua população uma vida mais digna. Outro fato imposto pelo constituinte com o intuito de efetivar essa proteção e reafirmando a importância do referido direito é de que os atentados dolosos contra a vida devem ser perseguidos criminalmente e processados penalmente pela via do júri, de acordo com a alínea "d" do inciso XXXVIII do artigo $5^{\circ}$ da Constituição Federal.

Reafirmando o dever de proteção do Estado, temos o entendimento doutrinário de Mendes; Coelho; Branco (2010, p. 446-447) de que "o Estado assumiu o dever de proteger e defender os indivíduos que se encontram sob a sua custódia". Desse modo, o dever de proteger a vida dos prisioneiros, o DOl:http://dx.doi.org/10.14393/Hygeia16047423 $\quad$ Hygeia $\quad$ v.16 $\quad$ p.11-24, $2020 \quad$ página 13 
que necessita de maiores cuidados necessários do que a simples preservação da existência desses indivíduos.

Assim se justifica o entendimento jurisprudencial de que o Estado tem responsabilidade civil diante da morte de detidos em presídios, mesmo que o homicídio não tenha se materializado por um agente público. Uma vez o indivíduo estando sob custódia do Estado, este tem o dever de zelar e preservar a vida digna, o bem mais precioso do ser humano.

$\mathrm{Na}$ legislação civilista brasileira, é considerado pessoa o ser humano que nasce com vida, conforme pode ser verificado no artigo $2^{\circ}$ do Código Civil Brasileiro (CCB). Porém na esfera penal, a vida humana é resguardada desde o período intrauterino, que, neste caso, é a razão pela qual o legislador atribuiu o crime de aborto para quem violar a vida do nascituro. Dois fatores que em relação à vida humana merecem ser mencionados e estão em constante evolução são os critérios usados na avaliação do óbito, de modo que antes ele era reconhecido quando ocorresse a parada cardiorrespiratória e, hoje, passa a ser entendido com a cessação da atividade cerebral, a conhecida morte encefálica. Estes são os parâmetros adotados como marco do início e do fim da vida humana no ordenamento jurídico brasileiro.

\section{DIGNIDADE DA PESSOA HUMANA}

A Dignidade da Pessoa Humana não é entendida pela maioria da doutrina como um direito, haja vista que não está conferida exclusivamente pelo ordenamento jurídico. É um princípio construído ao longo da história com o objetivo de proteger todo ser humano, independentemente de qualquer requisito ou condição, seja pela religião, posição social, ou qualquer outra diferenciação.

O princípio da Dignidade da Pessoa Humana é um dos fundamentos da República Federativa do Brasil e está expressamente previsto no inciso III do art. $1^{\circ}$ da Constituição Federal (CF) de 1988. Portanto constitui um núcleo em torno do qual orbitam todos os outros direitos fundamentais, o que constitui o princípio máximo em um Estado Democrático de Direito.

Considerado como o elemento da justiça, da liberdade e do desenvolvimento social, a consagração desse princípio como fundamento constitucional brasileiro impede que o Estado adote medidas que violem a dignidade da pessoa humana e impõe ao Poder Judiciário a obrigação de utilizá-lo como vetor na interpretação das normas vigentes. Logo, impõe aos poderes públicos também o dever de promover medidas para levar aos cidadãos o acesso a bens e utilidades indispensáveis a uma vida digna, devendo ser provido o mínimo existencial como, por exemplo, o acesso à saúde.

A Constituição Federal (1988) traz a dignidade da pessoa humana já gravada em seu Preâmbulo:

Nós, representantes do povo brasileiro, reunidos em Assembleia Nacional Constituinte para instituir um Estado Democrático, destinado a assegurar o exercício dos direitos sociais e individuais, a liberdade, a segurança, o bem-estar, o desenvolvimento, a igualdade e a justiça como valores supremos de uma sociedade fraterna, pluralista e sem preconceitos, fundada na harmonia social e comprometida, na ordem interna e internacional, com a solução pacífica das controvérsias, promulgamos, sob a proteção de Deus, a seguinte CONSTITUIÇÃO DA REPÚBLICA FEDERATIVA DO BRASIL.

Como pode ser visto, o espírito da nossa Constituição destaca a importância do reconhecimento da dignidade da pessoa humana como a garantia e exercício dos direitos humanos, mostrando assim que essa questão é de tamanha importância que o legislador entendeu em estampar no preâmbulo da nossa Constituição, apesar do mesmo não conter dispositivos normativos, servindo antes como um elemento importante de hermenêutica constitucional.

Além do mais, seu texto é constituído por uma linguagem cheia de expectativas e de anseios, para não falar de sonhos do que seria a ideia de que o país deveria lutar e alcançar. $E$, no direito brasileiro, a sua aplicabilidade deve estar presente tanto nas relações privadas quanto nas relações públicas, ou seja, entre particulares e Estado, concebendo a noção de dignidade humana na sua forma mais ampla, de modo a abranger todos os aspectos da vida humana. 


\section{DIREITO À LIBERDADE}

O Direito à liberdade, nas suas diversas formas deve ser observado sempre na ótica do indivíduo como parte de um grupo, o qual necessita de definições de regras para que se viva com menos conflitos dentro da sociedade. Essas regras foram se agregando ao longo do tempo e, hoje, conhecemos como o Direito.

Liberdade, no entendimento de Mendes; Coelho; Branco (2010, p.450) "é um dos elementos essenciais na estrutura da dignidade da pessoa humana, um vértice do sistema dos direitos fundamentais". Assim mostra a sua importância para o nosso ordenamento jurídico.

Quando falamos em liberdade como fundamento de um Estado Democrático de Direito, o seu conceito não envolve a faculdade que uma pessoa tem de fazer o que bem entender, pois, não é um direito absoluto, devendo ser entendido sob o aspecto de que essa temática constitui um estado em que são conferidos poderes para o indivíduo agir de acordo com a sua própria vontade.

Em suma, podemos falar que é o direito de fazer ou não fazer alguma coisa, senão em virtude da lei. Assim, considerando que o princípio da legalidade já consagrado pela nossa Carta Magna no inciso II do artigo $5^{\circ}$, a liberdade individual pode ser limitada apenas pela lei.

$\mathrm{O}$ artigo $1^{\circ}$ da Declaração Universal dos Direitos Humanos traz que todos os seres humanos nascem livres e iguais em dignidade e direitos. Dotados de razão e consciência, devem agir uns para com os outros em espírito de fraternidade. Dessa forma, a Declaração de Direitos Humanos reconhece a existência dos direitos da humanidade e anuncia uma nova era na evolução histórica. Se somos todos humanos, possuímos os mesmos direitos, a mesma dignidade e, consequentemente, devemos ser respeitados de maneira igualitária.

Portanto, partindo da premissa de que todos os homens nascem livres e iguais perante a lei, com direito e obrigações, podemos afirmar que a autonomia da vontade é um dos bens apontados com mais preciosidade dentre o rol de direitos tutelados pelo Estado Democrático de Direito.

Os argumentos acima tratados são importantes para situar teoricamente a temática abordada, pois como veremos, os procedimentos de internação adotados no Brasil se amparam, ou deveriam amparar nos valores previstos em nosso ordenamento jurídico.

\section{ESPÉCIES DE INTERNAÇÕES PSIQUIÁTRICAS}

O procedimento de internação esteve presente no Brasil por toda sua história, tendo início na idade média quando os primeiros relatos de internação se deram por parte dos leprosos, uma vez que essas pessoas contaminadas não tinham contato com o mundo exterior e eram esquecidos nos leprosários. Dessa maneira, o restante da população não correria o risco de contrair a doença. No final da idade média, mesmo com o desaparecimento da lepra e o esvaziamento dos leprosários, a imagem do leproso não saiu da sociedade.

Certamente, a medida de prisão foi no decorrer da história usada com o objetivo maior de isolar determinada pessoa da sociedade. Nesse sentido os ensinamentos de Foucault (1999, p. 143):

O exercício da disciplina supõe um dispositivo que obrigue pelo jogo do olhar; um aparelho onde as técnicas que permitem ver induzam a efeitos de poder, e onde, em troca, os meios de coerção tornem claramente visíveis aqueles sobre quem se aplicam.

O autor faz referência aos métodos utilizados para conseguir ter o poder sobre determinado indivíduo. No casso do presente trabalho, deve ser levado em conta a maneira que os internatos se dispunham. Aqui as pessoas eram internadas apenas para que pudessem controlá-las, já que não tinham como objetivo o tratamento. Quando o indivíduo se mostrava um obstáculo, ou mesmo se comportava de maneira diferente dos moldes sociais ou políticos, quase sempre era jogado em algum "observatório" para que ali ficasse isolado da sociedade.

Desse modo, atribuíam o poder à capacidade de monitoramento do indivíduo, se o internado tivesse sob vigilância ele, por certo, estaria sob controle. Assim, eram controlados pela política e pela camada da sociedade que estava protegida fora dos muros das prisões. 
A próxima vítima das internações foram os portadores de doenças venéreas que, da mesma forma, foram internados e submetidos à internação em ambientes coletivos, não para o seu tratamento, mas para ficarem isolados do restante da sociedade. Na sequência, foram os loucos, internados com o intuito maior de isolamento da sociedade e, atualmente, alcançando os viciados em tóxicos, o que nos mostra que, mesmo com todo o desenvolvimento da sociedade, sempre existiu uma figura marginalizada, excluída da comunidade.

O primeiro passo no plano da regulamentação das internações dado pelo Brasil foi o Decreto $\mathrm{n}^{\circ} 1.132$ do ano de 1.903, introduzindo um modelo de tratamento de doente mental. Era composto por 23 artigos que tratavam dos motivos que determinavam a internação e uma série de procedimentos necessários para a sua realização, até mesmo, referentes às penalidades caso fosse descumprido algum mandamento legal.

Mais tarde, o Brasil teve uma revolução nesse segmento no Poder Legislativo, com a conhecida reforma psiquiátrica. Com a Lei Federal 10.216/01, o quadro foi amenizado a partir do ano de 2001, pois incluiu outros tipos de tratamento, deixando a internação como última medida. Deve se ressaltar também a inserção de uma série de direitos relacionados às pessoas com transtornos mentais, definindo ainda a responsabilidade do Estado no tratamento de pessoas com sofrimentos psíquicos.

A respeito desta lei, explica Santos (2004, p. 55):

\begin{abstract}
Percebe-se, claramente, que, no Brasil, a referida lei 10.216/2001 representou um grande passo para a consolidação de uma visão mais humana e adequada acerca das "pessoas especiais", portadoras de transtornos mentais, servindo para a construção de diretrizes seguras na melhoria do convívio social destes indivíduos, especialmente na efetivação de princípios jurídicos afetos ao tratamento digno destes seres humanos, como a garantia para os mesmos de uma existência mais harmoniosa e feliz dentro dos seus limites e possibilidade.
\end{abstract}

$\mathrm{O}$ autor refere-se à proteção dos direitos constitucionais referentes à vida e a dignidade da pessoa humana, os quais são pilares básicos de nossa Carta Política e, concomitantemente, um fundamento para se justificar a medida de internação.

Ademais, no aparato legal, existe a portaria $n^{\circ}$ 2391/GM de dezembro de 2002, criada com o intuito de complementar a Lei 10.216/2001. Entretanto a reforma psiquiátrica continuou enfrentando questões éticas, com a mais polêmica de todas sendo a internação involuntária que já surgiu no universo psiquiátrico carregada de preconceito. A saber, muitas pessoas entendem que 0 ato de internar uma pessoa contra a sua vontade fere a liberdade que o paciente tem de optar por algum tipo de tratamento. Já por outro ponto de vista é enxergada como a única possibilidade de proteção ao paciente e de seus companheiros, pois o próprio não tem mais controle sob suas emoções, colocando a sua vida e a de quem os rodeia em perigo.

Sobretudo, para melhor entendimento do presente artigo, é importante que seja mencionado o conceito de internação psiquiátrica voluntária, involuntária e compulsória. Tal discriminação já foi satisfeita pelo legislador, no art. $6^{\circ}$ da Lei 10.216/2001:

Art. $6^{\circ} \mathrm{A}$ internação psiquiátrica somente será realizada mediante laudo médico circunstanciado que caracterize os seus motivos. Parágrafo único. São considerados os seguintes tipos de internação psiquiátrica:

I - internação voluntária: aquela que se dá com o consentimento do usuário;

II - internação involuntária: aquela que se dá sem o consentimento do usuário e a pedido de terceiro; e

III - internação compulsória: aquela determinada pela Justiça.

Como pode ser percebido, o referido mandamento legal disciplina os direitos e zela pela proteção das pessoas com transtornos mentais, trazendo ainda três tipos de internação psiquiátrica, a voluntária, a involuntária e a compulsória. A internação é indicada nos casos em que o paciente mantém um comportamento de alto risco, ou seja, quando coloca a própria vida e a de outros em risco, não respondendo a outros tratamentos terapêuticos e com dificuldades em alcançar a abstinência. 


\section{INTERNAÇÃO PSIQUIÁTRICA VOLUNTÁRIA E INVOLUNTÁRIA}

A internação voluntária está estabelecida no artigo $7^{\circ}$ da Lei $10.216 / 01$ e no parágrafo primeiro do artigo $3^{\circ}$ da portaria 2391/GM. Nessa espécie de internação, o indivíduo solicita voluntariamente sua internação ou mostra o seu consentimento com a medida, devendo ser assinada uma declaração mostrando que optou por tal regime de tratamento. Para a cessação da referida medida é feito uma solicitação escrita do paciente ou determinada pelo médico assistente.

Assim, a internação voluntária é aquela que o paciente declara por escrito que aceita o tratamento e, para tal ocorrência, devem ser observados alguns requisitos, como, por exemplo, o paciente deve ser maior e não estar civilmente interditado.

O critério utilizado para medir a capacidade psíquica aqui é o entendimento do paciente acerca de sua enfermidade e seus efeitos e, no caso do paciente não estiver apto para decidir sobre sua saúde, a modalidade de internação psiquiátrica será a involuntária. Uma vez que, no caso da internação involuntária é exigido um "responsável" que tomará as decisões, como uma analogia às pessoas interditadas.

Nesta modalidade de tratamento o paciente tem consciência da necessidade de internação e aceita fazer o tratamento terapêutico. Entretanto, só é possível tornar real a referida medida quando os pacientes ainda têm condições de avaliar as possíveis consequências trazidas pelo uso de substâncias que alteram as funções fisiológicas do corpo humano, optando por um tratamento. A maior dificuldade encontrada neste caso está justamente no restrito número de dependentes que reconhecem o próprio vício no início da dependência.

Por outro lado, temos a internação psiquiátrica involuntária é um procedimento médico imposto contra a vontade do paciente. Normalmente é feita quando a pessoa não está em condições de se auto determinar por ter as suas funções mentais alteradas por algum motivo, o que o impede de exercer a sua capacidade de percepção da realidade e de perceber os prejuízos causados pelas substâncias psicoativas. Os pacientes veem o consumo como um ato positivo e satisfatório e não aceitam o tratamento, colocando em risco a sua integridade física e mental, sem mencionar o potencial lesivo à sua família e a terceiros.

Nesse procedimento, conforme o $\S 1^{\circ}$ do artigo $8^{\circ}$ da Lei 10.216/01 e nos moldes do inciso I do artigo $4^{\circ}$ da Portaria 2391/GM, deverá no prazo de setenta e duas horas ser comunicado ao Ministério Público Estadual (MPE) pelo responsável técnico do estabelecimento em que se deu a internação. $O$ mesmo procedimento deverá ser adotado quando se der a respectiva alta. O término da medida se dá por solicitação escrita do familiar, ou responsável legal, ou quando estabelecido pelo especialista responsável pelo tratamento, nos conformes do parágrafo segundo do artigo $8^{\circ}$ da referida lei.

$\mathrm{O}$ artigo $4^{\circ}$ da Portaria estabelece que no caso da internação psiquiátrica involuntária deve ser feita uma notificação para o Ministério Público Estadual (MPE) e para a Comissão Revisora das Internações Psiquiátricas Involuntárias (CRIPI), constituída pelo gestor estadual do Sistema Único de Saúde (SUS). Tal notificação será feita como instrumento anexo à portaria, contendo os dados do usuário e os motivos da internação.

A comissão criada deverá ser multifuncional, ou seja, seus integrantes deverão ser de diferentes áreas, tendo no mínimo um psiquiatra ou clínico geral com habilitação em psiquiatria e um profissional de nível superior da área da saúde mental, conforme a portaria.

Além disso, em muitos casos de atendimento e tratamento involuntários, mesmo a internação ter se iniciada como involuntária, no transcorrer da terapia o paciente poderá desviar-se para a forma de tratamento voluntário, o que é possível quando ele passa a reconhecer e aceitar as mudanças que necessita para sua reabilitação. Sabe-se que a maioria dos dependentes de início nega o próprio vicio, todavia, com o avanço do tratamento e da maneira que o paciente vai recuperando sua consciência, ele aceita a medida e expressa o seu consentimento para com a terapia.

Nesse sentido, internação involuntária, pode ser vista como um instrumento para cumprir normas primordiais presentes na Declaração Universal dos Direitos Humanos e de nossa Lei Maior, resguardando o direito à vida, à liberdade e à segurança pessoal. Além do que o tratamento em regime de internação certamente tem maiores chances de recuperação, visto que o paciente se encontra longe da pressão e de conexões negativas que podem estar até mesmo no interior do leito familiar, enquanto o paciente está em fase de adaptação, de construção de um novo estilo de vida.

DOl:http://dx.doi.org/10.14393/Hygeia16047423 $\quad$ Hygeia $\quad$ v.16 $\quad$ p.11-24, $2020 \quad$ página 17


A internação psiquiátrica compulsória está prevista no caput do artigo $9^{\circ}$ da Lei $n^{\circ}$ 10.216/2001 e, conforme este imperativo legal, esta modalidade de internação psiquiátrica será determinada pelo juiz competente, levando-se em conta as condições de segurança do estabelecimento imprescindíveis para a salvaguarda do paciente, dos funcionários e dos demais internados.

Esta modalidade não é regulamentada pela Portaria $n^{\circ} 2391 / \mathrm{GM}$, conforme dispõe o parágrafo $4^{\circ}$ do artigo $3^{\circ}$ da referida norma. Consequentemente, esse tipo de internação deve ser constituída por meio do Poder Judiciário, através de um processo iniciado por parte de quem seja interessado, ou também pode ser acionada de ofício pelo juiz no decorrer de algum litígio específico.

Sobre esta modalidade temos o Tribunal de Justiça de Minas Gerais já se pronunciou:

EMENTA: INTERNAÇÃO INVOLUNTÁRIA. PRÉVIA INTERDIÇÃO DO INTERNANDO. DESNECESSIDADE. PACIENTE EM USO DE DROGAS ILÍCITAS. EXISTÊNCIA DE VIOLAÇÃO AO DIREITO À SAÚDE. PACIENTE QUE DESEJA INTERNAR-SE VOLUNTARIAMENTE. POSSIBILIDADE. -A internação compulsória prescinde de prévia interdição, até porque o objetivo da internação é a recuperação da saúde do interditando, que, como ressaltado, encontra-se incapaz para responder, momentaneamente, pelos atos da vida civil, em razão da dependência química alegada - sendo o tratamento e o direito à saúde um direito de todos, como se verifica da leitura do artigo 196 da Constituição Federal.

- Como tantas vezes já ficou consignado, o SUS tem sua estrutura descentralizada para melhor atendimento do cidadão. Assim, não podem as pessoas políticas que compõem o sistema eximir-se de cumprir as obrigações que lhe forem impostas sob o simples argumento de não lhe competir determinada tarefa - fornecimento de medicamentos, internação, tratamento fora de domicílio etc..

- O assunto é polêmico (até entre os médicos), mas a questão do uso de drogas e álcool é atualmente de inadiável relevância e importância social, que requer permanente e cada vez mais aguda atenção das entidades federadas, em todos os níveis de governo, estas que não se podem esquivar das obrigações que lhes são constitucionalmente traçadas, sob o argumento (sempre invocado) da ausência de estrutura física, de pessoal ou de projetos e/ou ações de implementação de uma política de prevenção, tratamento e recuperação de dependentes químicos.

- É verdade que há dificuldades orçamentárias. Todos os sabem. Mas todos sabem também que os recursos existem. O que não existe é a aplicação destes recursos, que se evaporam como água. Dos mais de 400 milhões de reais disponibilizados pela SENAD (Secretaria Nacional de Políticas sobre Drogas) apenas cerca de 20\% foram aplicados. O Brasil disponibiliza menos de $1 / 2$ (meio) leito para cada Município (2 mil e quinhentos leitos para todo o País) (Fonte: "Estado de Minas" de 11.7.2011 pag. 7). Ora, num quadro assim caótico falar-se em reserva do possível é quase um abuso.

- Como bem anotou o Exmo. Ministro Celso Mello, quando do julgamento do AgRg no RE 271.286-8/RS: "O caráter programático da regra inscrita no art. 196 da Carta Política - que tem por destinatários todos os entes políticos que compõem, no plano institucional, a organização federativa do Estado brasileiro - não pode converter-se em promessa constitucional inconsequente, sob pena de o Poder Público, fraudando justas expectativas nele depositadas pela coletividade, substituir, de maneira ilegítima, o cumprimento de seu impostergável dever, por um gesto irresponsável de infidelidade governamental ao que determina a própria Lei Fundamental do Estado. (...)".

Se o paciente deseja internar-se voluntariamente - e o psiquiatra do CAPS recomenda esta internação, deve ser ela preferida à internação compulsória. (TJMG - Agravo de Instrumento-Cv 1.0148.14.001035-3/001, Relator(a): Des.(a) Wander Marotta , $7^{\mathrm{a}}$ CÂMARA CíVEL, julgamento em 14/10/2014, publicação da súmula em 17/10/2014)

O Poder Judiciário entende que a internação é de responsabilidade do Estado como um todo, União, os Estados, o Distrito Federal e os Municípios, sendo todos responsáveis solidariamente pela prestação dos serviços da saúde, conforme previsto no artigo 23 da Constituição Federal (CF). Nesse caso, também os julgadores entendem pela necessidade de prévia interdição do paciente, uma vez que este passará por um tratamento buscando a recuperação de sua saúde, visando devolver ao indivíduo sua capacidade mental que, em decorrência da dependência encontra-se lesada. 
Outro fator importante nessa forma de internação é de que nela não tem a necessidade de autorização de um familiar, podendo, até mesmo, ser feita por um médico que ateste a imprescindibilidade do tratamento psiquiátrico por meio da internação e demonstre que o paciente não tem controle sob suas ações e que suas funções físicas e mentais estão comprometidas.

Nesse tipo de internação o fator determinante é a prova inequívoca da condição de dependente do viciado em tóxico. Em outras palavras, o que vai embasar a internação é que a perda do controle do indivíduo se deu pela dependência química. Como se pode verificar, nem todo usuário é dependente químico e, como se sabe, a Lei 10.216/01 confere proteção aos portadores de transtornos mentais (e viciados em tóxicos), consequentemente é preciso provar inquestionavelmente que o indivíduo é dependente químico.

A ação de internação compulsória dispensa o prévio procedimento de interdição, exigindo-se para tanto laudo médico atestando a sua incapacidade para os atos da vida civil, nos termos do art. $4^{\circ}$, II, do Código Civil. Para evidenciar o cuidado que deve ser empregado na adoção desta medida, temos o entendimento do Tribunal de justiça de São Paulo.

A INTERNAÇÃO INVOLUNTÁRIA. Dependente de álcool e drogas. Esposa que alega estado de pavor de todos os familiares diante dos constantes ataques e ameaças do agravado. Ausência de prova pericial a demonstrar a necessidade da internação. A internação compulsória é medida excepcional. Lei 10.216/01 que serve a proteger as pessoas portadoras de transtornos mentais. Ausência de indícios que tratamento extra-hospitalar não se mostrará suficiente. Ausência de laudo médico recente indicando os motivos da interdição. Decisão mantida. Recurso desprovido. (TJ-SP - Al: 01425792020138260000 SP 0142579-20.2013.8.26.0000, Relator: Ana Lucia Romanhole Martucci, Data de Julgamento: 13/03/2014, 6ª Câmara de Direito Privado, Data de Publicação: 14/03/2014)

Diante deste entendimento a internação compulsória deve ser uma medida adotada em último caso, já que seria a última tentativa no tratamento, pois tal ação não pode ser usada de qualquer forma, devendo ficar comprovada a necessidade do tratamento para o dependente. Para assim não desrespeitar nenhuma garantia constitucional, a saber, que o intuito maior dessa modalidade de tratamento é de promover a cura da dependência e resguardar a saúde do internado, não promovendo apenas o isolamento do indivíduo e atendendo ao desejo de parte da sociedade de uma "limpeza social".

\section{A DEPENDÊNCIA QUÍMICA}

A dependência química é uma doença considerada como um transtorno mental, ou seja, é a situação em que o indivíduo tem o seu comportamento alterado por alguma substancia psicoativa. Para o dependente, a droga é tão necessária para a sua vida como algumas das necessidades naturais do corpo e psíquicas, como o alimento e a água. É importante mencionar também que existem algumas substâncias, como medicamentos e o álcool que, embora não estejam entre as drogas ilícitas, podem causar dependência em pessoas predispostas como qualquer outra droga, ilegal ou não.

Ao tratar sobre as drogas e as causas de dependência, deve ser enfatizado as causas que levam a internação, como a relação direta das drogas com a violência. Nesse sentido, Passagli (2009: p. 54) diz que:

Há uma relação muito estreita entre drogas ilícitas e resolução de problemas de forma violenta com emprego de armas, especialmente armas de fogo, na realidade cotidiana da sociedade brasileira, afetando principalmente os jovens das áreas urbanas da periferia dos grandes centros.

Sendo assim, o suposto bem estar da sociedade poderia ser um argumento muito influente para justificar a medida de internação no caso dos dependentes químicos. Visto que uma pessoa com dependência em tóxicos, para manutenção do seu vício, é autor de situações constrangedoras, tanto de acordo com os padrões éticos da sociedade como no sentido legal.

Para conseguir satisfazer o seu vício, o dependente acaba por infringir as normas legais e acaba cometendo crimes para conseguir dinheiro e, assim, comprar drogas. Por tal fato, a maioria da população liga diretamente o uso de drogas com o emprego de violência como forma de suprir os vícios e as necessidades dos usuários de tóxicos.

DOI:http://dx.doi.org/10.14393/Hygeia16047423 $\quad$ Hygeia $\quad$ v.16 $\quad$ p.11-24, 2020 página 19


A dependência não deve ser tratada de qualquer maneira, devendo ser diagnosticada como uma doença e independente do seu grau deve ser tratada como tal e protegida pela Lei 10.210/01, necessitando de assistência médica, apoio familiar e equilíbrio espiritual e psicológico para ajudar o usuário na luta contra a vontade incessante de consumir a droga ilícita causadora da dependência.

Dessa maneira, podemos concluir que a medida de internação, quando não manchada pelos vícios da sociedade capitalista, consegue atingir o seu objetivo, como evitar que o usuário cause danos à sociedade e a si mesmo, como também alimenta para o interno e suas famílias a esperança de que o vício seja sanado ou se torne controlável.

Entretanto, algumas clínicas são encontradas de tal forma que não conseguem mostrar nem o mínimo de dignidade que se espera de um local para tratamento de um ser humano. Algumas clínicas apresentam condições insalubres para se viver, outras maltratam os pacientes na intenção de controlá-los e várias outras formas que desrespeitam a dignidade desses indivíduos. Desse modo, algumas casas de tratamento não estão preparadas para cuidar de pessoas com transtornos mentais, podendo até mesmo agravar o estado dos internos.

Assim, percebemos uma obrigação do Estado em fiscalizar todas as etapas do tratamento desses pacientes, verificando se as clínicas têm estrutura adequada e se seus empregados são capacitados para lidar com as situações do seu ofício.

\title{
OS EFEITOS DA DEPENDÊNCIA QUÍMICA
}

Primeiramente, para melhor entendimento acerca do tema tratado, é preciso suscitar um conceito acerca da dependência química. Segundo Varella (2013, texto digital, pág. 6):

\begin{abstract}
Toda vez que o cérebro é submetido a estímulos repetitivos carregados de conteúdo emocional, os circuitos de neurônios envolvidos em sua condução se modificam para tentar perpetuar a sensação de prazer obtida.

[...] Na seleção natural das espécies, levaram vantagem reprodutiva aquelas que desenvolveram mecanismos de recompensa ao prazer com o objetivo de criar a necessidade de buscar sua repetição. Para o organismo, em princípio, tudo o que traz bem-estar é bom e deve ser repetido. Se não fosse assim, nós nos esqueceríamos de nos alimentar, de fazer sexo ou de procurar a temperatura mais agradável na hora de dormir.

[...] Por um capricho da natureza, entretanto, a estimulação repetida do centro do prazer pode provocar ativação irreversível do centro da busca, de modo que este permanece estimulado mesmo quando o uso da droga já não traz mais prazer nenhum.
\end{abstract}

Como pode ser observado, a relação de dependência química está diretamente anexada ao sentimento de prazer e, em outras palavras, seria a mesma satisfação de saciar a sede em um dia quente. Esse sentimento humano interfere no comportamento, gerando uma intensa ansiedade para o corpo conseguir suprir sua angústia, o que faz com que o dependente químico perca o controle do próprio corpo.

Consequentemente, podemos entender o motivo que leva o dependente químico a passar por condições desumanas para ter o vício alimentado, tanto que muitas pessoas passam a roubar e largam o trabalho e a família para morar na rua.

Outra consequência que pode ser verificada nos casos de dependência química é que a droga traz sérias lesões ao organismo, tardando funções no cérebro e do corpo, podendo surgir quadros que apresentam alucinações e constante sensação de perseguição. Nessa fase, fica claro que o dependente não é capaz de ter consciência dos seus atos, pois a droga assumiu o controle e mantém o indivíduo como seu escravo.

Sendo assim, fica evidente a fragilidade do ser humano em se deparar com as drogas, pois essas substâncias possuem um alto poder de dependência. Dessa forma fica evidenciada a necessidade de se encontrar uma medida eficaz na luta contra as drogas, já que, porventura, a internação psiquiátrica involuntária não seria a solução desse problema, podendo ser considerada uma importante arma para livrar o indivíduo do seu vício. 


\section{A RESPONSABILIDADE CIVIL DO DEPENDENTE QUÍMICO}

A respeito da capacidade, o artigo $1^{\circ}$ do Código Civil Brasileiro $(\mathrm{CCB})$, traz a regra geral que toda pessoa é capaz de direitos e deveres na ordem civil. Porém, acontece que nem todas as pessoas tem a aptidão para responder sempre pelos seus atos. Por isso a própria legislação civil se encarregou de trazer a exceção à regra geral:

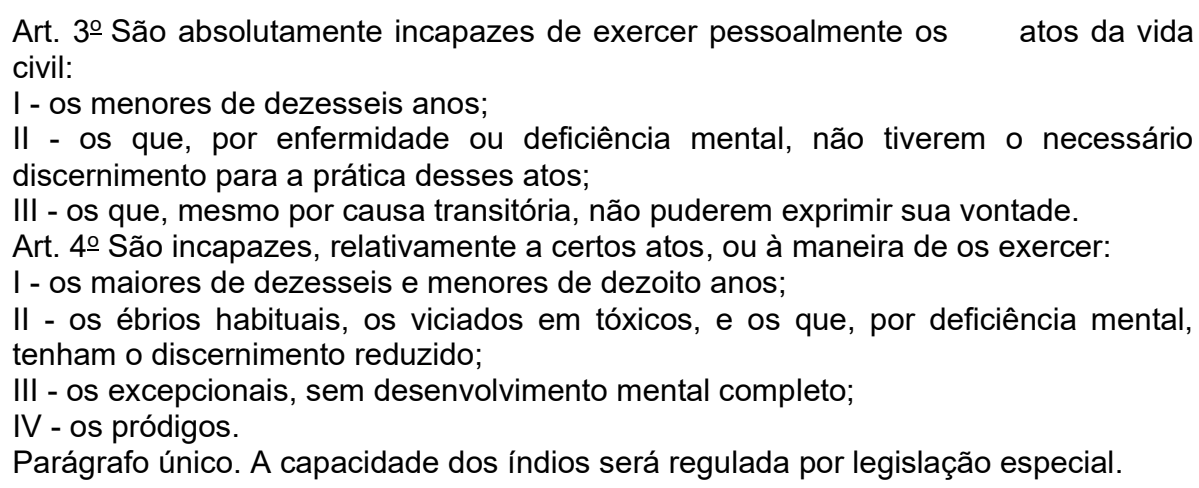

Como demonstrado pela legislação civilista, os dependentes químicos e portadores de transtornos mentais são incapazes de exercer por si só os atos da vida civil, na medida de sua enfermidade. Especificamente, os dependentes vão se enquadrar em relação ao grau que sua servidão com as drogas se encontra. Caso seja uma situação transitória é usada a regra do inciso II do artigo $3^{\circ}$ do CCB e serão considerados absolutamente incapazes, necessitando de um curador para representálos nos atos da vida civil. Já no caso se uma situação que ocorra constantemente ficará enquadrada no inciso II do artigo $4^{\circ}$ do CCB e terão decretada sua capacidade relativa e, consequentemente, precisam de um curador para acompanhar os seus interesses.

Os dependentes químicos estão sujeitos ao processo de curatela transcrito no inciso III do artigo 1.767 do CCB que poderá ser promovido pelos pais ou tutores, pelo cônjuge ou parente e pelo Ministério Público, conforme o artigo 1.768 do CCB.

Para Gonçalves (2012), a responsabilidade pode resultar tanto de normas morais como jurídicas, separada ou concomitantemente. Tudo vai depender do caso concreto, pois uma infração pode ser, muitas vezes, proibida pela lei moral ou religiosa ou pelo direito. Por outro lado determinada situação pode fugir dos padrões éticos da sociedade e ao mesmo tempo ser legal para o direito.

Já na esfera da moral, a responsabilidade repercute em um espaço mais amplo do que o tratado pelo direito, pois a mesma atua no campo da consciência individual. O ser humano vê a responsabilidade perante sua convicção formada, ou seja, se acordo com a sua consciência o indivíduo se vê responsável ou não por determinada situação. Mas essa responsabilidade "moral" não tem repercussão jurídica.

\section{CONSTITUCIONALIDADE DA MEDIDA TERAPÊUTICA}

A internação compulsória apesar de no passado ser usada para camuflar problemas sociais, foi, em contrapartida a única tentativa no tratamento de pessoas com sofrimento psíquico na época, pois, como não conheciam uma cura para a doença, os tiravam da sociedade e internavam-nos em clínicas ou hospitais, acreditavam que assim a doença não contaminaria o resto da população.

Nos dias atuais, diante do contexto social, sustenta uma grande polêmica em razão de ser questionável sua eficácia. Mais recentemente foi considerada uma mediada sugerida como política pública para usuários de drogas. Os adeptos desta proposta citam que a maioria dos dependentes químicos apresenta um quadro de transtorno mental. Já aqueles que discordam, argumentam a respeito das práticas de abuso ocorrido em clínicas de tratamento e a ineficácia do procedimento.

Além disso, a sociedade clama por uma medida mais eficiente na luta contra as drogas, uma vez que, com o passar dos dias, só aumenta o número de dependentes químicos e os crimes ligados ao uso de tóxicos.

A internação psiquiátrica é uma importante ação na reabilitação de dependentes químicos quando é

DOl:http://dx.doi.org/10.14393/Hygeia16047423 $\quad$ Hygeia $\quad$ v.16 $\quad$ p.11-24, 2020 página 21


seguida no seu objetivo principal, o qual seja o tratamento dos viciados em tóxicos e a sua reinserção no meio social. Diferentemente do que acontece quando a medida não é acompanhada pelo Estado, quando a clínica em que o dependente é internado não tem uma estrutura adequada a chance de eficiência do tratamento é mínima.

O problema neste caso, só é agravado, neste momento é comum a ocorrência de situações de maus tratos, violência física, humilhações e até mesmo a prática de tortura física e psicológica, podendo gerar danos irreparáveis para o paciente. O que vai de encontro ao propósito final da medida, o de ressocialização. Em contrapartida uma parte dos doutrinadores tem o entendimento de que a medida de internação não é uma forma de prisão e sim um tratamento médico. A respeito do assunto temos as palavras de Capez: (2011, texto digital, pág. 4):

\begin{abstract}
A internação compulsória por ordem judicial pressupõe uma ação efetiva e decidida do Estado no sentido de aumentar as vagas em clínicas públicas criadas para esse fim, sob pena de o comando legal inserto na lei $n^{\circ} 10.216 / 2001$ tornar-se letra morta. Espera-se que o poder público não se porte como um mero espectador, sob o cômodo argumento do respeito ao direito de ir e vir dos dependentes químicos, mas, antes, faça prevalecer seu direito à vida.
\end{abstract}

Como pode ser entendido, a medida de internação é uma aposta na luta contra a dependência, pois como já foi exposto o anteriormente, o dependente perde o controle sob o seu corpo e mente. Nesse momento surge a figura da internação como instrumento que vem afastá-lo do ambiente nocivo e venenoso em que se encontra. Visto que sem nenhum auxílio o viciado tem poucas chances de se libertar da escravidão do vício.

Uma das dificuldades enfrentadas na medida de internação é que parte da população trata o usuário de drogas como criminosos, apesar de que os profissionais da área veem a dependência como um transtorno mental, logo, aos olhos dos mais leigos existe um preconceito nessa relação e querem de qualquer forma prender tais viciados, não se preocupando com o tratamento, da mesma forma que no passado queriam apenas o isolamento dos antissociais.

Além disso, muitos indagam a eficácia da medida de internação psiquiátrica, com o argumento de que esse tratamento viola os direitos de liberdade, haja vista que assemelham a privação da liberdade do indivíduo com a prisão. Mas esse tratamento tem a finalidade de desintoxicar o dependente químico uma vez que este é tratado como paciente e não como prisioneiro, bem como neste caso não existe o caráter punitivo da pena privativa de liberdade.

Portanto, a medida de internação psiquiátrica não viola as garantias constitucionais, contando que internar não é prender e para que qualquer grupo social conviva com menos atritos é preciso que se estabeleçam algumas regras. As garantias constitucionais não são absolutas e quando o seu direito afeta o direito de outrem, neste momento ocorre uma ponderação de direitos, assim como é feito em nossa Constituição no caso de conflitos entre princípios, eles são ponderados para que continue vivendo de maneira balanceada uns com os outros.

\title{
CONSIDERAÇÕES FINAIS
}

Conclui-se que até o momento a sociedade brasileira não conseguiu criar uma política pública eficaz na luta contra as drogas. Nem tampouco uma medida que consiga respeitar plenamente todas as garantias e princípios constitucionais das pessoas com sofrimento psíquico. $\mathrm{O}$ que deixa, assim, a sociedade desprotegida e insegura, já que grande parte de população se sujeita a viver cercada por grandes muros na busca de uma segurança que o Estado não consegue garantir, enquanto a classe menos favorecida convive no seu dia a dia com a violência.

Um dos fatores responsáveis por essa violência está ligado ao uso de drogas, pois os usuários agem como seus escravos e buscam de qualquer forma manter o seu vício. $\mathrm{E}$, nos dias atuais, o número de pessoas envolvidas com as drogas, ao mesmo passo da violência, só aumenta.

Tratando a internação compulsória como uma opção viável para reinserção e melhoria de vida dos seres atormentados pelas drogas, tal medida está de acordo com o ordenamento jurídico. Levando-se em conta a ponderação dos bens conflitantes, a internação fundamenta-se nos princípios de proteção à vida, à saúde e a dignidade da pessoa humana, devendo prevalecer sob o direito de liberdade, ainda que cada caso mereça uma atenção especial.

DOl:http://dx.doi.org/10.14393/Hygeia16047423 $\quad$ Hygeia $\quad$ v.16 $\quad$ p.11-24, 2020 página 22


Há de se ressalvar que a medida de internação não pode ser vista como uma prisão, como mencionado no decorrer do trabalho, uma vez que tal tratamento não tem o caráter punitivo da pena privativa de liberdade. A referida medida deve ser vista com bons olhos como um procedimento médico, devendo ser realizada por profissionais competentes.

Como se sabe, o dependente químico não está no controle de suas emoções, não domina o equilíbrio entre corpo e mente, devendo ser visto como uma pessoa com transtornos mentais que necessita de proteção da Lei $10.2016 / 01$, de tratamento médico e de outros profissionais de saúde. O problema não é resolvido quando colocamos esses indivíduos em prisões, o que, de outra forma, só agrava a questão. Sem mencionar a ineficácia do atual sistema brasileiro de encarceramento, que não reeduca ninguém, antes, ao contrário, funciona mais como uma "escola do crime".

Sob outro ponto de vista, pode ser verificado através deste trabalho que os direitos fundamentais presentes em nossa Constituição, resultados de nossas conquistas históricas, adquiriram importância universal, que estabelece o dever do Estado em promover e garantir essas garantias fundamentais a todos, sem distinção. Constatou-se ainda que esses direitos, em determinados casos, podem se chocar, de modo que, no presente estudo verifica-se, em regra, que a vida, a saúde e a dignidade da pessoa humana se sobrepõem ao direito de liberdade e autonomia da vontade.

Ademais, entendemos o direito à vida como uma condição elementar para a existência dos outros direitos, inclusive a liberdade, haja vista que sem a vida não é possível garantir nenhum outro direito sequer.

Desse modo, é possível a utilização da medida de internação de dependentes químicos com a finalidade de proteger tanto as famílias quanto os usuários. Contudo, nem todos os usuários são dependentes químicos, por isso o Estado deve cumprir o papel de fiscalização em todo o procedimento de internação, como observado pela lei 10.216/2001, para assim zelar pela dignidade dos internados. Sabemos, outrossim, que é dever do Estado combater a droga como um problema de saúde pública bem como assegurar as garantias fundamentais expostos em nossa Carta Magna.

Contudo, podemos concluir que a medida de internação compulsória, quando feita sob o amparo do Estado, com estrita observância aos princípios e valores contidos na legislação pertinente, é absolutamente viável e tem respaldo constitucional, pois o seu objetivo respeita os direitos fundamentais inerentes à pessoa humana e visa a desintoxicação do dependente, o seu tratamento e sua reinserção na sociedade, zelando por sua vida e saúde.

\section{REFERÊNCIAS}

BOBBIO, Norberto. A Era dos Direitos. 2010. Disponível em http://direitoufma2010.files.wordpress.com/2010/05/norberto-bobbio-a-era-dos-direitos.pdf. Acesso em 15 nov. 2018.

BRASIL. Constituição (1988). Constituição da República Federativa do Brasil. In: Vade Mecum. Obra coletiva de autoria da Editora Revista dos Tribunais com a colaboração de Darlan Barroso e Marco Antônio Araújo Júnior. 5 ed. atual. e ampl. São Paulo: Revista dos Tribunais, 2013.

. Código Civil. In: Vade Mecum. Obra coletiva de autoria da Editora Revista dos Tribunais com a colaboração de Darlan Barroso e Marco Antônio Araújo Júnior. 5 ed. atual. e ampl. São Paulo: Revista dos Tribunais, 2013.

Decreto 1.132 de 22 de dezembro de 1903: Reorganiza a Assistência a Alienados. Disponível em: http://www2.camara.leg.br/legin/fed/decret/1900-1909/decreto-1132-22-dezembro-1903-585004publicacaooriginal-107902-pl.html. Acessado em: 10 out. 2018.

. Lei 10.216 de 06 de abril de 2001: Dispõe sobre a proteção e os direitos das pessoas portadoras de transtornos mentais e redireciona o modelo assistencial em saúde mental. Disponível em:

http://www.planalto.gov.br/ccivil_03/leis/leis_2001//10216.htm. Acessado em: 10 out. 2018.

Portaria 2391/GM de 26 de dezembro de 2002: Regulamenta o controle das internações psiquiátricas involuntárias (IPI) e voluntárias (IPV) de acordo com o disposto na Lei 10.216, de 6 de abril de 2002, e os procedimentos de notificação da Comunicação das IPI e IPV ao Ministério Público DOI:http://dx.doi.org/10.14393/Hygeia16047423 Hygeia $\quad$ v.16 $\quad$ p.11-24, 2020 página 23 
pelos estabelecimentos de saúde, integrantes ou não do SUS. Disponível em: http://dtr2001.saude.gov.br/sas/PORTARIAS/Port2002/Gm/GM-2391.htm. Acessado em: 10 out. 2018.

CAPEZ, Fernando. Drogas: internação compulsória e educação. Artigo. 2011. Disponível em: http://www1.folha.uol.com.br/fsp/opiniao/fz1907201108.htm. Acesso em 15 nov. 2018.

FOUCAULT, Michel. História da loucura na idade clássica. 7. ed. São Paulo:Perspectiva, 2004.

GONÇALVES, Carlos Roberto.Direito Civil Brasileiro. 10ª. Ed, São Paulo: Saraiva, 2012.

MENDES, Gilmar Ferreira, COELHO, Inocêncio Mártires, BRANCO, Paulo Gustavo Gonet. Curso de Direito Constitucional. 5. ed. São Paulo: Editora Saraiva, 2010.

MINAS GERAIS. Tribunal de Justiça de Minas Gerais. Agravo de Instrumento. Internação Involuntária. Agravo de Instrumento n. 1.0148.14.001035-3/001 MG 0179663-81.2014.8.13.0000 Relator: Wander Marotta. Data de Julgamento: 14/10/2014, $7^{\mathrm{a}}$ Câmara Cível, Data da Publicação: $17 / 10 / 2014$. Disponível

em http://www5.tjmg.jus.br/jurisprudencia/pesquisaPalavrasEspelhoAcordao.do?\&numeroRegistro=1\&tota ILinhas $=52$ \&paginaNumero $=1$ \&linhasPorPagina $=1$ \&palavras=interna $\% E 7 \% E 30 \% 20$ involuntaria\&pesq uisarPor=ementa\&pesquisaTesauro=true\&orderByData=1\&referenciaLegislativa=Clique $\% 20 \mathrm{na} \% 20 \mathrm{lu}$ pa\%20para\%20pesquisar\%20as\%20refer\%EAncias\%20cadastradas...\&pesquisaPalavras=Pesquisar \&. Acesso em 20 out. 2018.

PASSAGLI, Marcos. Toxicologia forense: teoria e prática. 2. ed. São Paulo: Editora Millennium, 2009.

SANTOS, Marcos André. Saúde mental e o direito. São Paulo: Editora Método, 2004.

SÃO PAULO. Tribunal de Justiça de São Paulo. Agravo de Instrumento. Internação Involuntária. Agravo de Instrumento n. 01425792020138260000 SP 0142579-20.2013.8.26.0000, Relator: Ana Lucia Romanhole Martucci, Data de Julgamento: 13/03/2014, 6a Câmara de Direito Privado, Data de Publicação: 14/03/2014. Disponível em <http://tj-sp.jusbrasil.com.br/jurisprudencia/123599327/agravode-instrumento-ai-1425792020138260000-sp-0142579-2020138260000. Acesso em 20 out. 2018.

VARELLA, Drauzio. Prazer Compulsivo. 2013. Artigo. Disponível em: http://drauziovarella.com.br/dependencia-quimica/alcoolismo/prazer-compulsivo/\#. Acesso em: 15 nov. 2018.

Alcoolismo. 2013. Artigo. Disponível em:http://drauziovarella.com.br/dependencia-quimica/alcoolismo/alcoolismo/. Acesso em: 15 nov. 2018. 